\title{
Bernat Metge
}

* zwischen I340 und I346 in Barcelona (Spanien)
† zwischen März und Juni I4I3 in Barcelona (Spanien)

Abenteuerliches Leben im Dienst des Prinzen Don Juan; von Boccaccio und Llull beeinflusste Prosa; übersetzte Petrarca; bedeutender Prosaautor des katalanischen Spätmittelalters.

\section{Buch vom Glück und von der Klugheit / Libre de Fortuna e Prudència}

Die allegorische Dichtung entstand um I38I, erschien jedoch erst I9Io bis I9I2 im Druck. Im Metrum der ’noves rimades` (gereimten Erzählungen), in II94 paarweise reimenden Achtsilblern, erzählt ein Erzähler in der Ichform, wie er, geplagt von Zweifeln und Skrupeln, bei einem Spaziergang vor Tagesanbruch am Strand von Barcelona einem alten Mann begegnet, der ihn in ein Boot lockt und ohne Segel und Ruder aufs Meer hinausstößt. Er gerät auf eine Insel und gelangt dort an ein prächtiges, allerdings zur Hälfte verfallenes Schloss. Als dessen Herrin tritt ihm Fortuna entgegen, die ohne Rücksicht auf Recht und Verdienst willkürlich Glück und Unglück verteilt, nach jedem Schritt vorwärts zwei Schritte zurückgeht und in der Hand ein unaufhörlich sich drehendes Rad trägt, das Rad des Schicksals. Als der Erzähler mit ihr zu hadern beginnt, verstößt sie ihn aus dem Schloss, doch nun erscheint ihm, von sieben Jungfrauen (den sieben freien Künsten) begleitet, Prudència, die Klugheit, und versucht, ihn mit Gedanken aus De consolatione philosophiae des Boethius über sein Missgeschick und die Ungerechtigkeit der Welt zu trösten. Der Leser erfährt nicht, ob sie dabei Erfolg hat, sondern nur, dass der Autor in demselben Boot zurückfährt und noch vor Sonnenaufgang wieder in Barcelona ankommt. Die allegorischen Themen - Seefahrt, Insel, Schloss - waren mittelalterliches Gemeingut, das der Autor bei Alain de Lille (Alanus ab Insulis), Jean de Meung und Guillem de Torroella finden konnte.

Metge war der erste volkssprachliche Autor der Iberischen Halbinsel, bei dem unter dem Einfluss des Frühhumanismus die Erschütterung des christlich-mittelalterlichen Weltbildes spürbar wird.

AURELIO FUENTES ROJO 